\title{
High ERCC1 expression predicts cisplatin-based chemotherapy resistance and poor outcome in unresectable squamous cell carcinoma of head and neck in a betel-chewing area
}

Tai-Jan Chiu, ${ }^{4,6 \dagger}$, Chang-Han Chen ${ }^{2,4,5 \dagger}$, Chih-Yen Chien ${ }^{2,4}$, Shau-Hsuan Li ${ }^{1,4}$, Hsin-Ting Tsai ${ }^{2,4}$ and Yi-Ju Chen ${ }^{3 *}$

\begin{abstract}
Background: This study was to evaluate the effect of excision repair cross-complementation group 1(ERCC1) expression on response to cisplatin-based induction chemotherapy (IC) followed by concurrent chemoradiation (CCRT) in locally advanced unresectable head and neck squamous cell carcinoma (HNSCC) patients.

Methods: Fifty-seven patients with locally advanced unresectable HNSCC who received cisplatin-based IC followed by CCRT from January 1, 2006 through January 1, 2008. Eligibility criteria included presence of biopsy-proven HNSCC without a prior history of chemotherapy or radiotherapy. Immunohistochemistry was used to assess ERCC1 expression in pretreatment biopsy specimens from paraffin blocks. Clinical parameters, including smoking, alcohol consumption and betel nuts chewing, were obtained from the medical records.

Results: The 12-month progression-free survival (PFS) and 2-year overall survival (OS) rates of fifty-seven patients were $61.1 \%$ and $61.0 \%$, respectively. Among these patients, thirty-one patients had low ERCC1 expression and forty-one patients responded to IC followed by CCRT. Univariate analyses showed that patients with low expression of ERCC1 had a significantly higher 12-month PFS rates (73.3\% vs. $42.3 \%, p<0.001)$ and 2 -year OS (74.2 vs. $44.4 \%$, $\mathrm{p}=0.023)$ rates. Multivariate analysis showed that for patients who did not chew betel nuts and had low expression of ERCC1 were independent predictors for prolonged survival.
\end{abstract}

Conclusions: Our study suggest that a high expression of ERCC1 predict a poor response and survival to cisplatinbased IC followed by CCRT in patients with locally advanced unresectable HNSCC in betel nut chewing area.

\section{Background}

Squamous cell carcinoma of the head and neck (HNSCC) is the sixth most common cancer in the world [1] and two-thirds of these patients initially present with locally advanced disease [2]. In Taiwan, HNSCC rates $4^{\text {th }}$ in male cancer-related deaths [3] among middle-aged male patients between 25 and 45 years old [4]. Most HNSCC patients in Taiwan diagnosed with advanced disease are young men. The main risk factors of this unique patient population are the

\footnotetext{
* Correspondence: yiru6307@gmail.com

† Contributed equally

${ }^{3}$ Department of Pathology, E-Da hospital, Kaohsiung, Taiwan

Full list of author information is available at the end of the article
}

habitual consumption of cigarettes, alcohol, and betel nuts $[5,6]$.

Although patients with locally advanced HNSCC receive surgery and radiotherapy, less than $30 \%$ will be cured, and locoregional recurrences or distant metastases develop in $40 \%$ to $60 \%$ patients $[7,8]$, which occurs with a median survival rate of no more than 6 months [9]. Some studies have demonstrated improved locoregional control and overall survival by adding chemotherapy to radiotherapy concurrently [10]. The Meta-Analysis of Chemotherapy in Head and Neck Cancer (MACH-NC) study showed that concomitant chemoradiation is superior to RT alone for patients with advanced HNSCC and chemoradiotherapy (radiotherapy plus concurrent chemotherapy) has become the standard of care for patients with unresectable

\section{Biomed Central}

(c) 2011 Chiu et al; licensee BioMed Central Ltd. This is an Open Access article distributed under the terms of the Creative Commons Attribution License (http://creativecommons.org/licenses/by/2.0), which permits unrestricted use, distribution, and reproduction in any medium, provided the original work is properly cited. 
HNSCC $[11,12]$. However, the best chemotherapeutic regimen combined with RT in HNSCC has yet to be defined; the concomitant administration of cisplatin represents a widely accepted choice. It has been reported that induction chemotherapy (IC) with cisplatin and fluorouracil (PF) benefits this disease [12-14] and results in a significantly improved 5 -year survival rate in patients with locally advanced disease compared to surgery and standard radiotherapy alone [12].

In Taiwan, for public healthy insurance, cisplatin is the backbone of the chemotherapy regimen as a component of IC and CCRT in the treatment of locally advanced HNSCC. Its main cytotoxic activity is based on the formation of DNA adducts, which cause inter- and intrastrand cross-linking. These DNA cross-links are recognized and removed by the nucleotide excision repair pathway which arms to guard the integrity of the genome $[15,16]$. The enzyme excision repair cross-complementation group 1(ERCC1) plays a rate limiting role in the nucleotide excision repair pathway, and its expression has been associated with survival in patients with various malignancies [17-19]. The relation between ERCC1 expression and resistance to platinum compounds had been found by some clinical studies in patients with advanced-stage gastric, ovarian, colorectal, esophageal, and non-small-cell lung cancers $[15,17,19-21]$. However, there are only few studies to elucidate the relationship between ERCC1 expression and prognosis in patients with locally advanced HNSCC treated with CCRT. The purpose of this study was to evaluate whether the immunohistochemical expression status of ERCC1 can predict the treatment response and survival in patients with unresectable HNSCC being treated with cisplatin-based IC followed by CCRT.

\section{Methods}

\section{Patients and treatment}

A total of 57 patients with pathologically proven locally advanced inoperable HNSCC were treated with IC followed by CCRT between January 1, 2006 and January 1, 2008 at Kaohsiung Chang-Gung Medical Center (Taiwan). To be included, all the patients had to have a biopsy-proven previously untreated IV (M0) unresectable squamous cell carcinoma of the head and neck region, have no synchronous primary tumors, and be $\geq 18$ years old. In addition, the patients had to have a performance status (PS) of $\leq 2$ on the Eastern Cooperative Oncology Group (ECOG) scale, adequate bone marrow, hepatic and renal function (creatinine clearance $>60 \mathrm{ml} / \mathrm{min}$ ), and a computed tomography or magnetic resonance image scan of the head and neck region within three weeks prior to the initiation of treatment. The clinicopathological information including age, gender, tumor (T) stage, nodal $(\mathrm{N})$ status, TNM stage, and survival was obtained from the clinical records. The histories of betel nuts chewing, alcohol and tobacco use were obtained by our detailed questioning at the patients' first visit to the otolaryngology clinic of the hospital.

The IC consisted of 2 cycles of cisplatin $75 \mathrm{mg} / \mathrm{m} 2$ and fluorouracil (5-FU) $(1000 \mathrm{mg} / \mathrm{m} 2)$ given as a continuous 24-h infusion for four days. The two cycles of IC were administered every four weeks. After IC, all patients received CCRT. During the CCRT, cisplatin was administered weekly at a dose of $40 \mathrm{mg} / \mathrm{m} 2$. RT was delivered 3-4 weeks after the completion of the IC with a linear accelerator. Ondansentron \pm dexamethasone was used as antiemetic treatment. The response to IC followed by CCRT was assessed according to the World Health Organization (WHO) criteria. Surgery was performed six to twelve weeks after completion of IC followed by CCRT regimen for patients who had residual disease. Surgery was also allowed for patients who did not complete chemoradiation and had resectable residual disease at the primary site or in the neck. Patients were evaluated by CT scan or MRI of the head and neck every three months. Informed consent was obtained from study participants and protocol for this study was approved by the Institutional Review Boards of Chang-Gung Medical Center (Taiwan).

\section{Immunohistochemical staining for ERCC1}

Adjacent non-cancerous and tumor HNSCC tissue samples were selected by a pathologist based on diagnosis and microscopic morphology. Adjacent non-cancerous tissue and tumor tissues were fixed with $10 \%$ buffered formalin embedded in paraffin and decalcified in 10\% EDTA solution. Representative blocks of the formalinfixed, paraffin-embedded tissues were cut to $4 \mathrm{~mm}$ and deparaffinized with xylene and rehydrated in a series of ethanol washes $(100,90,80$, and $70 \%)$. Slides were washed with phosphate-buffered saline (PBS) and treated with $3 \% \mathrm{H}_{2} \mathrm{O}_{2}$ for 30 minutes to block endogenous peroxidase activity. Next, the sections were microwaved in $10 \mathrm{mM}$ citrate buffer, $\mathrm{pH}$ 6.0, to unmask the epitopes. After antigen retrieval, the sections were incubated with diluted anti-ERCC1 antibody (monoclonal; 8F1; Thermo scientific, Fremont, CA, USA; 1:100), for $3 \mathrm{~h}$ followed by washing with PBS. Horseradish peroxidase/Fab polymer conjugate (PicTure ${ }^{\mathrm{TM}}$-Plus kit; Zymed, South San Francisco, CA, USA) was then applied to the sections for 30 min followed by washing with PBS. Finally, the sections were incubated with diaminobenzidine for $5 \mathrm{~min}$ to develop the signals. A negative control was run simultaneously by omitting the primary antibody.

\section{Evaluation of ERCC1 expression}

Two pathologists, who were unaware of the clinical data, evaluated the ERCC1 staining independently under a 
light microscope at a magnification of $\times 400$. The pathologists recorded whether tumor or stromal cells expressed ERCC1. The staining intensity was graded on a scale of 0-3, using adjacent nonmalignant cells as a reference (intensity 2). Five images of representative areas were acquired for each specimen. The percentage of positive nuclei was calculated for each specimen, and a proportion score was assigned ( 0 if $0 \%, 0.1$ if $1-9 \%, 0.5$ if $10-49 \%$, and 1.0 if $\geqq 50 \%$ ). The proportion score was multiplied by the staining intensity to obtain a final semi-quantitative $\mathrm{H}$ score. The median value of the $\mathrm{H}$ score was chosen as the cutoff point for separating low and high levels of ERCC1 expression [22].

\section{Statistical analysis}

Statistical analyses of $2 \times 2$ tables of categorical variables were performed using Pearson's $x^{2}$ test or Fisher's exact test, where appropriate. Survival probability analyses were performed using the Kaplan-Meier method. Survival was calculated from the date of start of chemotherapy to the date of death or most recent follow-up. Progression free survival (PFS) was defined as the time from the date of first chemotherapy to the date of first observation of disease progression, or relapse, or death due to any cause. Significance between group differences was assessed by the log-rank test. Multivariate analyses were performed using a logistic regression model for response and Cox regression models for PFS and overall survival (OS). Factors with p-values $<0.05$ in univariate analyses were examined with multivariate regression models. All statistical tests were two-sided, with significance defined as $p<0.05$. Analyses were performed using SPSS version 13.

\section{Result}

Patient characteristics

The median age of the patients was 53 years (range 3672 years), and fifty-five (96.5\%) out of 57 were men. Ten patients had IVA and 47 had stage IVB disease. The most common sites were the oral cavity $(24 / 57,42.1 \%)$, followed by the oropharynx $(21 / 57,36.8 \%)$ (Table 1$)$. The median radiation they received was 6600 cGy. Nineteen patients received more than 70 Gy of radiation

Table 1 Correlation between expression of ERCC1 and clinicopathological factors of HNSCC

\begin{tabular}{|c|c|c|c|c|c|c|}
\hline & \multirow[b]{2}{*}{ No. of patients } & \multicolumn{2}{|c|}{ ERCC1 } & \multirow[t]{2}{*}{$P$} & \multirow{2}{*}{$\begin{array}{c}\text { Multivariates analysis } \\
\text { OR }(95 \% \mathrm{Cl})\end{array}$} & \multirow[t]{2}{*}{$\mathbf{P}$} \\
\hline & & Low expression & High expression & & & \\
\hline \multicolumn{7}{|l|}{ Age } \\
\hline$\leqq 50$ & $22(38.6 \%)$ & $11(50.0 \%)$ & $11(50.0 \%)$ & 0.598 & 1 & \\
\hline$>50$ & $35(61.4 \%)$ & $20(57.1 \%)$ & $15(42.9 \%)$ & & $0.47(0.11,2.11)$ & 0315 \\
\hline \multicolumn{7}{|l|}{ Gender } \\
\hline Male & $55(96.5 \%)$ & $30(54.5 \%)$ & $25(45.5 \%)$ & 1.000 & 1 & \\
\hline Female & $2(3.5 \%)$ & $1(50 \%)$ & $1(50 \%)$ & & $48.36(0.54,4313.32)$ & 0.090 \\
\hline \multicolumn{7}{|l|}{ Tumor Site } \\
\hline oral cavity & $24(42.1 \%)$ & $11(45.8 \%)$ & $13(54.2 \%)$ & 0.057 & 1 & \\
\hline oropharynx & $21(36.8 \%)$ & $10(47.6 \%)$ & $11(52.4 \%)$ & & $1.58(0.35,7.07)$ & 0.549 \\
\hline hypopharynx/Larynx & $12(21.1 \%)$ & $10(83.3 \%)$ & $2(16.7 \%)$ & & $0.096(0.007,1.33)$ & 0.081 \\
\hline \multicolumn{7}{|l|}{ Stage } \\
\hline IVa & $10(17.5 \%)$ & 7 (70.0\%) & $3(30.0 \%)$ & 0.319 & 1 & \\
\hline $\mathrm{IVb}$ & $47(82.5 \%)$ & $24(51.1 \%)$ & $23(48.9 \%)$ & & $3.33(0.39,27.89)$ & 0.276 \\
\hline \multicolumn{7}{|l|}{ T stage } \\
\hline $1 / 2$ & $6(10.5 \%)$ & $6(100 \%)$ & $0(0 \%)$ & $0.027^{*}$ & 1 & \\
\hline $3 / 4$ & $51(89.5 \%)$ & $25(49.0 \%)$ & $26(51.0 \%)$ & & Indeterminate & 0.999 \\
\hline \multicolumn{7}{|l|}{ N stage } \\
\hline negative & $12(21.1 \%)$ & $5(41.7 \%)$ & 7 (58.3\%) & 0.503 & 1 & \\
\hline positive & 45 (78.9\%) & $26(57.8 \%)$ & $19(42.2 \%)$ & & $0.75(0.15,3.64)$ & 0.727 \\
\hline \multicolumn{7}{|l|}{ Alcohol drinking } \\
\hline Never & $11(17.2 \%)$ & $4(36.4 \%)$ & 7 (63.6\%) & 0.318 & 1 & \\
\hline Yes & $46(82.8 \%)$ & 27 (58.7\%) & 19 (41.3\%) & & $2.49(0.31,19.88)$ & 0.388 \\
\hline \multicolumn{7}{|l|}{ Smoking } \\
\hline Never & $9(15.8 \%)$ & $3(33.3 \%)$ & $6(66.7 \%)$ & 0.275 & 1 & \\
\hline Yes & $48(84.2 \%)$ & $28(58.3 \%)$ & $20(41.7 \%)$ & & $1.77(010,30.72)$ & 0.695 \\
\hline \multicolumn{7}{|l|}{ Betel nuts } \\
\hline Never & $20(35.1 \%)$ & $8(40.0 \%)$ & $12(60.0 \%)$ & 0.109 & 1 & \\
\hline Yes & 37 (64.9\%) & $23(62.2 \%)$ & $14(37.8 \%)$ & & $12.78(1.28-127.62)$ & $0.030^{*}$ \\
\hline
\end{tabular}


dose. All patients had received their IC and 53 patients completed the followed up CCRT.

\section{Clinico-pathologic factors of HNSCC patients with ERCC1 expression}

To investigate whether the increased expression of ERCC1 was associated with various prognostic factors, such as age, gender, and TNM pathologic classification, we classified the patients into two groups based on their immunohistochemical results (low vs. high ERCC1 expression) (Figure 1A and 1B). The median H score for HNSCC was 1.5. Twenty-six (46\%) tumors had an $\mathrm{H}$ score of more than 1.5 and were thus defined as having a high expression of ERCC1. As can be seen in Table 1 a summary of result of the ERCC1 immunostaining of the cancer cells and its correlation with the clinicopathologic variables, the high and low ERCC1 expression groups did not significantly with regard to age, gender, TNM tumor stage, and node metastatic status, alcohol drinking or smoking (Table 1). The high ERCC1 expression group had a higher T stage (T3-4) $(p=0.027)$. Those with squamous cell carcinoma of the hypopharynx/larynx were found to have marginal lower expression of ERCC1. Interestingly, in our multivariate regression model, patients who habitually chewed betel nuts had a significantly higher expression of ERCC1.

\section{Relationship between treatment response and ERCC1 expression}

The overall response rate after CCRT for all patients was $72 \%$ (41/57 with 28 complete responses and 13 partial responses; 9 had stable disease and 7 progressive disease). Patients with low expression of ERCC1 had a higher treatment response $(28 / 31,90.3 \%)$ than the high expression group $(13 / 26,50 \%)(p=0.002$, Table 2$)$.

\section{Relationship between survival and ERCC1 expression}

The median follow-up was 24.0 months (6 - 46 months). The overall 12-month PFS rate was $61.1 \%$ and the 2- year OS rate was $61.0 \%$. The 12-month PFS for patients with low expression of ERCC1 was $73.3 \%$ compared with $42.3 \%$ for patients with high expression of ERCC1 $(\mathrm{p}<0.001$, Figure 2A). The 2-year OS rate was significantly higher in patients with low expression of ERCC1 $(74.2 \%)$ than in those with high expression of ERCC1 (44.4\%) $(\mathrm{P}=0.023$, Figure $2 \mathrm{~B})$. Univariate analysis showed that tumor stage and tumor location were important factors affecting the OS and PFS (Table 3), though ERCC1 expression and betel nuts chewing were the prognostic factors in OS by multivariate analysis according to Cox regression model (Table 4).

\section{Discussion}

It is of special interest that in our study that specimens from patients who habitually chewed betel nuts had high expression of ERCC1. Betel nut chewing is a common habit among those who live in South Asia, including Taiwan [23], and is known as one cause of HNSCC [24]. There are many compounds in the betel nut that have been correlated with carcinogenesis; the habit of chewing betel nut is related to persistent damage of the oral mucosa as well as precancerous lesions such as leukoplakia and erythroplakia, and oral submucosal fibrosis [25]. In previous reports, overexpression of epidermal growth factor receptor (EGFR) was found to be involved in betel nut-related HNSCC $[26,27]$. However, the relationship between betel nut and ERCC1 expression has not been reported before. In this study, we find tissue samples from patients with habitual consumption of betel nuts showed significant correlation with high ERCC1 expression. This finding awaits confirmation by prospective studies with large numbers of patients.

In this study, Forty-six percent of the patients with inoperable HNSCC had a high expression of ERCC1. Patients with a high expression of ERCC1 had a lower treatment response rate to IC followed by CCRT than those with low expression of ERCC1. In addition, low

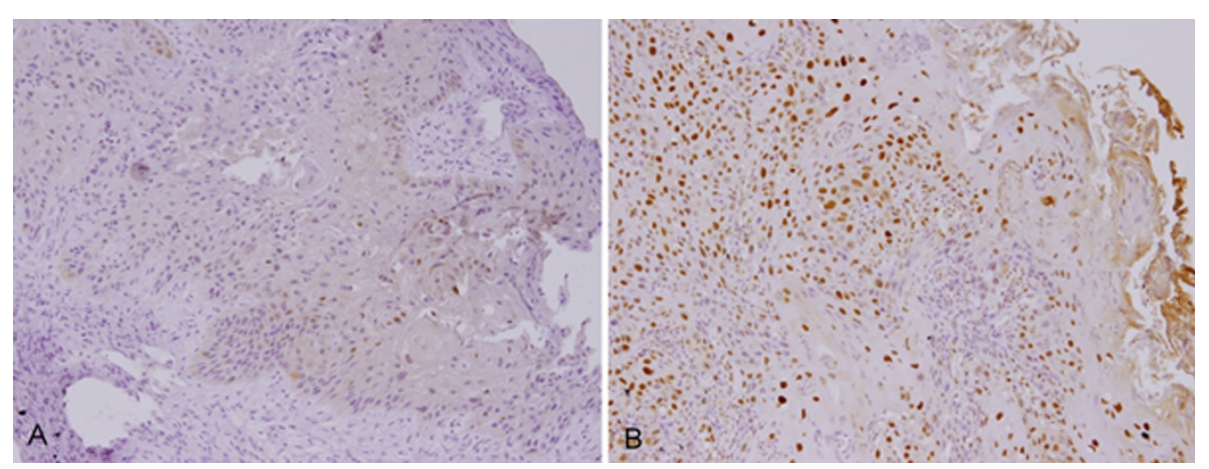

Figure 1 Analysis of ERCC1 expression in head and neck squamous cell carcinoma. ERCC1 expression was determined using immunohistochemistry. A) Low ERCC1 expression (200x magnification). B) High ERCC1 expression (200x magnification). 
Table 2 Relationship between treatment response and clinicopathological factors

\begin{tabular}{|c|c|c|c|c|c|}
\hline & \multicolumn{3}{|c|}{ Treatment response } & \multicolumn{2}{|c|}{ Multi-variates } \\
\hline & CR/PR & SD/PD & $\mathbf{P}$ & $\begin{array}{c}\text { OR } \\
(95 \% \mathrm{Cl})\end{array}$ & $\mathbf{P}$ \\
\hline \multicolumn{6}{|l|}{ Age } \\
\hline$\leqq 50$ & 15 (68.2\%) & 7 (31.8\%) & 0.844 & 1 & \\
\hline$>50$ & $26(74.3 \%)$ & $9(25.7 \%)$ & & $0.53(0.07,3.65)$ & 0.520 \\
\hline \multicolumn{6}{|l|}{ Gender } \\
\hline male & 39 (70.9\%) & $16(29.1 \%)$ & 1.000 & 1 & \\
\hline female & $2(100 \%)$ & $0(0 \%)$ & & Indeterminate & 1.000 \\
\hline \multicolumn{6}{|l|}{ Tumor Site } \\
\hline oral cavity & $15(62.5 \%)$ & $9(37.5 \%)$ & $0.049^{*}$ & 1 & \\
\hline oropharynx & $14(66.7 \%)$ & 7 (33.3\%) & & $1.29(0.21,7.70)$ & 0.778 \\
\hline hypopharynx/larynx & $12(100 \%)$ & 0 & & Indeterminate & 0.998 \\
\hline \multicolumn{6}{|l|}{ Stage } \\
\hline IVa & $10(100 \%)$ & $0(0 \%)$ & $0.048^{*}$ & 1 & \\
\hline $\mathrm{IVb}$ & 31 (66.0\%) & $16(34.0 \%)$ & & Indeterminate & 0.998 \\
\hline \multicolumn{6}{|l|}{ T stage } \\
\hline $1 / 2$ & $6(100 \%)$ & $0(0 \%)$ & 0.170 & 1 & \\
\hline $3 / 4$ & $35(68.6 \%)$ & $16(31.4 \%)$ & & Indeterminate & 0.999 \\
\hline \multicolumn{6}{|l|}{ N stage } \\
\hline negative & $8(66.7 \%)$ & $4(25.0 \%)$ & 0.732 & 1 & \\
\hline positive & $33(73.3 \%)$ & $12(26.7 \%)$ & & $0.75(0.06,8.54)$ & 0.818 \\
\hline \multicolumn{6}{|l|}{ Radiation } \\
\hline$\leqq 6000$ cGy & $14(70.0 \%)$ & $6(30.0 \%)$ & 1.000 & 1 & \\
\hline$>6000$ cGy & $27(75.7 \%)$ & $10(24.3 \%)$ & & $0.22(0.02,2.43)$ & 0.222 \\
\hline \multicolumn{6}{|l|}{ Alcohol drinking } \\
\hline never & 9 (81.8\%) & $2(18.2 \%)$ & 0.710 & 1 & 0.120 \\
\hline yes & $32(69.6 \%)$ & $14(30.4 \%)$ & & $0.08(0.004,1.89)$ & \\
\hline \multicolumn{6}{|l|}{ Smoking } \\
\hline never & 7 (77.8\%) & 2 (22.2\%) & 1.000 & 1 & \\
\hline yes & 34 (70.8\%) & $14(29.2 \%)$ & & $2.97(0.10,86.59)$ & 0.526 \\
\hline \multicolumn{6}{|l|}{ Betel nuts } \\
\hline never & $16(80.0 \%)$ & $4(20.0 \%)$ & 0.491 & 1 & \\
\hline yes & $25(67.6 \%)$ & $12(32.4 \%)$ & & $0.38(0.03,4.55)$ & 0.452 \\
\hline \multicolumn{6}{|l|}{ ERCC1 } \\
\hline low expression & $28(90.3 \%)$ & 3 (9.7\%) & $0.002^{*}$ & 1 & \\
\hline high expression & $13(20.0 \%)$ & $13(50.0 \%)$ & & $0.07(0.009,055)$ & $0.012^{*}$ \\
\hline
\end{tabular}

$\mathrm{CR}$, complete response; $\mathrm{PR}$, partial response; $\mathrm{SD}$, stable disease; $\mathrm{PD}$, disease progression; $\mathrm{RTO}$, radiotherapy; $\mathrm{OR}$, odds ratio; $\mathrm{Cl}$, confidence interval.
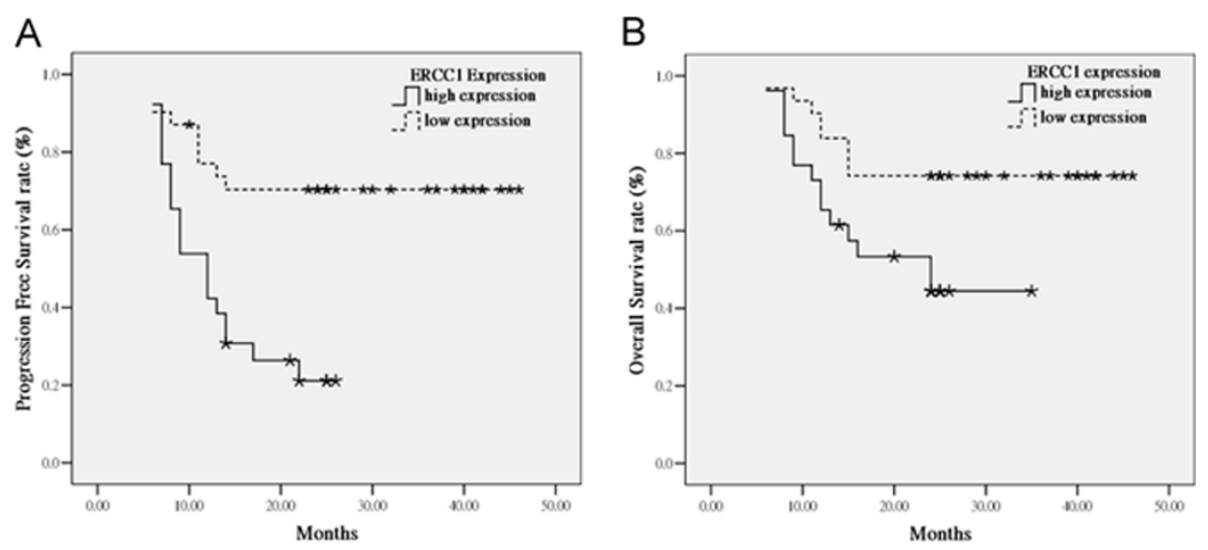

Figure 2 Kaplan-Meier estimates of the probability of survival. (A) PFS according to ERCC1 expression. PFS: progression free survival. (B) OS according to ERCC1 expression. OS: overall survival. 
Table 3 Univariate analyses of prognostic factors for survival

\begin{tabular}{|c|c|c|c|c|c|}
\hline Variables & $\begin{array}{c}\text { No. of } \\
\text { patients }\end{array}$ & $\begin{array}{l}\text { Cumulative 12-month preogresion free survival } \\
\text { rate }\end{array}$ & $P$ & $\begin{array}{c}\text { Cumulative 2-year overall survival } \\
\text { rate }\end{array}$ & $P$ \\
\hline \multicolumn{6}{|l|}{ Age } \\
\hline$<50$ & 22 & $49.0 \%$ & 0.725 & $50.0 \%$ & 0.152 \\
\hline$\geqq 50$ & 35 & $68.6 \%$ & & $68.0 \%$ & \\
\hline \multicolumn{6}{|l|}{ Gender } \\
\hline male & 55 & $61.5 \%$ & 0.878 & $65.2 \%$ & 0.553 \\
\hline female & 2 & $50.0 \%$ & & $50.0 \%$ & \\
\hline \multicolumn{6}{|l|}{ Site } \\
\hline oral cavity & 24 & $41.7 \%$ & & $45.5 \%$ & 0.093 \\
\hline oropharynx & 21 & $66.7 \%$ & 0.101 & $66.6 \%$ & \\
\hline $\begin{array}{l}\text { Hypopharynx/ } \\
\text { larynx }\end{array}$ & 12 & $81.8 \%$ & $0.035^{*}$ & $83.3 \%$ & \\
\hline \multicolumn{6}{|l|}{ Stage } \\
\hline IVa & 10 & $80.0 \%$ & 0.119 & $90.0 \%$ & $0.049^{*}$ \\
\hline $\mathrm{IVb}$ & 47 & $57.2 \%$ & & $54.7 \%$ & \\
\hline \multicolumn{6}{|l|}{ T stage } \\
\hline $0-2$ & 6 & $66.7 \%$ & 0.396 & $66.7 \%$ & 0.694 \\
\hline $3-4$ & 51 & $60.5 \%$ & & $60.3 \%$ & \\
\hline \multicolumn{6}{|l|}{$\mathrm{N}$ stage } \\
\hline negative & 12 & $50.0 \%$ & 0.837 & $72.9 \%$ & 0.350 \\
\hline positive & 45 & $57.3 \%$ & & $57.8 \%$ & \\
\hline \multicolumn{6}{|l|}{ Radiation } \\
\hline$\leqq 6000$ cGy & 20 & $55.0 \%$ & 0.304 & $55.0 \%$ & 0.412 \\
\hline$>6000 \mathrm{cGy}$ & 37 & $64.5 \%$ & & $64.1 \%$ & \\
\hline \multicolumn{6}{|l|}{ Alcohol } \\
\hline never & 11 & $63.6 \%$ & 1.000 & $63.6 \%$ & 0.754 \\
\hline yes & 46 & $60.6 \%$ & & $64.8 \%$ & \\
\hline \multicolumn{6}{|l|}{ Smoking } \\
\hline never & 9 & $66.7 \%$ & 0.614 & $66.7 \%$ & 0.679 \\
\hline yes & 48 & $60.1 \%$ & & $60.0 \%$ & \\
\hline \multicolumn{6}{|l|}{ Betel nuts } \\
\hline never & 20 & $70.0 \%$ & 0.638 & $74.0 \%$ & 0.123 \\
\hline yes & 37 & $56.3 \%$ & & $54.1 \%$ & \\
\hline \multicolumn{6}{|l|}{ ERCC1 } \\
\hline low expression & 31 & $73.7 \%$ & $0.001^{*}$ & $74.2 \%$ & $0.023^{*}$ \\
\hline high expression & 26 & $42.3 \%$ & & $44.4 \%$ & \\
\hline
\end{tabular}

ERCC1 expression was associated with a significantly longer PFS and OS. Multivariate analysis revealed that low expression of ERCC1 to be an independent factor associated with a lower risk of cancer death (HR 0.31, $p=0.010)$. Our findings are consistent with previous report of an increase in tumor response and prolongation of OS in patients treated by cisplatin based IC followed by CCRT for locally advanced HNSCC [28-30]. Moreover, the relationship between the expression of ERCC1 and tumor response or survival has also been demonstrated in esophageal cancer patients treated with chemoradiotherapy [31] and non-small cell lung cancer treated with cisplatin-based adjuvant chemotherapy [22].
However, in patients with locally advanced HNSCC treated with cetuximab-based CCRT, ERCC1 expression has not been found to predict treatment response [32]. In this context, we assume that pre-therapeutic ERCC1 protein levels within tumor cells might be correlated with their cisplatin-related DNA damage repair capacity. A less efficient DNA-repair capacity could affect the cellular response to DNA damage and could thus render cancer cells more sensitive to cisplatin. In addition, Nix et al. has reported an association between both ERCC1 and XRCC1 and radioresistance in laryngeal tumors [33].

Cetuximab is an IgG1 monoclonal antibody against the ligand-binding domain of EGFR. Cetuximab binds 
Table 4 Risk factors affecting 1-year disease free survival and 2-year overall survival rate determined by Cox regression analysis

\begin{tabular}{|c|c|c|c|c|}
\hline \multirow[t]{2}{*}{ Variables } & PFS & \multirow[b]{2}{*}{$P$} & \multicolumn{2}{|l|}{ OS } \\
\hline & HR $(95 \% \mathrm{Cl})$ & & HR $(95 \% \mathrm{Cl})$ & $P$ \\
\hline \multicolumn{5}{|l|}{ ERCC1 expression } \\
\hline Low vs High & $0.27(0.12-0.61)$ & 0.001 & $0.31(0.13-0.75)$ & 0.010 \\
\hline \multicolumn{5}{|l|}{ Betel nuts } \\
\hline Never vs Used & NE & 0.647 & $0.35(0.13-0.98)$ & 0.045 \\
\hline
\end{tabular}

$\mathrm{Cl}$, confidence interval; $\mathrm{HR}$, Hazard ratio.

EGFR, sequesters the receptor in the cytoplasm and eventually targets it for degradation. In vitro studies have demonstrated that this antibody enhances the radio-sensitivity in HNSCC cells $[34,35]$ through several processes, such as DNAPK, which are reviewed in Mukesh et al. [36]. When cetuximab is combined with radiation, it has been found to inhibit the nuclear translocation of the complex between DNA-dependent protein kinase and EGFR and then delayed the DNA repair [37-39]. Oxaliplatin induced double-strand breaks [40]. When cetuximab was combined with oxaliplatin, cetuximab reduced the expression of ERCC-1 and other genes involved in DNA replication initiation $[41,42]$. We might find a subgroup of patients with high ERCC1 expression having poor response to cisplatin-based IC and CCRT that is particularly benefited from treatments with cetuximab and other chemotherapeutic agents.

Our study has several limitations. First, the study was based on a retrospective analysis and only there were only 57 patients accumulated over a short period. The primary tumor site was also heterogeneous, and the prognosis of HNSCC is dependent on the primary tumor site. In our study, those oral cavity cancer had the worst prognosis and laryngeal cancer a good prognosis, although we found no significant difference in our multi-variate analyses. Second, some patients with IC followed by CCRT had a partial response and received further salvage surgery. Patients who receive salvage surgery had significantly longer PFS and OS rates than those who did not receive such surgery. The salvage surgery may affect the relationship between ERCC1 expression and survival. It also suggested that those patients with lower expression of ERCC1 would benefit from the potential downstage by our treatment protocol and become resectable. Our study was comprised only a small number of patients for each tumor location, and so we may need more homogeneous and a larger number of patients to validate this finding.

\section{Conclusion}

This present study suggests that ERCC1 mediated repair of DNA damage contributes to the clinical outcome in patients with locally advanced inoperable HNSCC treated with cisplatin-based IC and CCRT. In this context, it is strongly recommended that tissue be collected to assess ERCC1 expression before cisplatin-based induction chemotherapy and concurrent chemoradiotherapy. If patients with habit of betel nuts chewing may have higher chance of high ERCC1 expression, they should consider other treatment approach modalities.

\section{Acknowledgements \\ Sources of support: Chang Gung Memorial Hospital Grant (CMRPG890471 to Yi-Ju Chen, CMRPG890921 to Chang-Han Chen and CLRPG871342 to Samuel HH Chan).}

\section{Author details}

'Department of Medical Oncology, Chang Gung Memorial HospitalKaohsiung Medical Center, Chang Gung University, College of Medicine, Kaohsiung, Taiwan. ${ }^{2}$ Department of Otolaryngology, Chang Gung Memorial Hospital-Kaohsiung Medical Center, Chang Gung University College of Medicine, Kaohsiung, Taiwan. ${ }^{3}$ Department of Pathology, E-Da hospital, Kaohsiung, Taiwan. ${ }^{4}$ Kaohsiung Chang Gung Head and Neck Oncology Group, Cancer Center, Chang Gung Memorial Hospital-Kaohsiung Medical Center, Kaohsiung, Taiwan. ${ }^{5}$ Center for Translational Research in Biomedical Sciences, Chang Gung Memorial Hospital-Kaohsiung Medical Center. ${ }_{6}^{6}$ Institute of Clinical Medical Sciences, Chang Gung University, Kaohsiung, Taiwan.

\section{Authors' contributions}

TJC and CHC conceived the study design, carried out and coordinated immunohistochemical examinations of tumor specimens and data analysis, and drafted the manuscript. CYC and HTT participated in the interpretation of data and conducted immunohistochemistry analysis. SHL collected the clinical data of patients and performed statistical data analysis. YJC coordinated the study and were involved in drafting the manuscript and revised it critically. All authors read and approved the final manuscript.

\section{Competing interests}

The authors declare that they have no competing interests.

Received: 27 December 2010 Accepted: 23 March 2011

Published: 23 March 2011

\section{References}

1. Greenlee RT, Hill-Harmon MB, Murray T, Thun M: Cancer statistics, 2001. CA Cancer J Clin 2001, 51:15-36.

2. Kim ES, Kies M, Herbst RS: Novel therapeutics for head and neck cancer. Curr Opin Oncol 2002, 14:334-342.

3. Chien $\mathrm{CY}$, Su CY, Chuang HC, Fang FM, Huang HY, Chen $\mathrm{CH}$, Chen $\mathrm{CM}$, Huang CC: Comprehensive study on the prognostic role of osteopontin expression in oral squamous cell carcinoma. Oral Oncol 2009, 45:798-802.

4. Department of Health EY, R.O.C.: Cancer Registry Annual Report in Taiwan Area. Taipei. Department of Health, Executive Yuan, ROC 2006.

5. Ko YC, Huang YL, Lee CH, Chen MJ, Lin LM, Tsai CC: Betel quid chewing, cigarette smoking and alcohol consumption related to oral cancer in Taiwan. J Oral Pathol Med 1995, 24:450-453.

6. Hsieh LL, Wang PF, Chen IH, Liao CT, Wang HM, Chen MC, Chang JT, Cheng AJ: Characteristics of mutations in the p53 gene in oral squamous cell carcinoma associated with betel quid chewing and cigarette smoking in Taiwanese. Carcinogenesis 2001, 22:1497-1503.

7. Adelstein DJ, Li Y, Adams GL, Wagner H, Kish JA, Ensley JF, Schuller DE, Forastiere AA: An intergroup phase III comparison of standard radiation therapy and two schedules of concurrent chemoradiotherapy in patients with unresectable squamous cell head and neck cancer. $J$ Clin Oncol 2003, 21:92-98.

8. Forastiere AAMM, Weber RS, et al: Long-term results of Intergroup RTOG 91-11: a phase III trial to preserve the larynx - induction cisplatin/5-FU and radiation therapy versus concurrent cisplatin and radiation therapy versus radiation therapy. J Clin Oncol 2006, 24(Suppl):284s, abstract. 
9. Vokes EE, Weichselbaum RR, Lippman SM, Hong WK: Head and neck cancer. N Engl J Med 1993, 328:184-194.

10. Forastiere AA, Goepfert H, Maor M, Pajak TF, Weber R, Morrison W, Glisson B, Trotti A, Ridge JA, Chao C, et al: Concurrent chemotherapy and radiotherapy for organ preservation in advanced laryngeal cancer. $N$ Engl I Med 2003, 349:2091-2098.

11. Argiris A: Update on chemoradiotherapy for head and neck cancer. Curr Opin Oncol 2002, 14:323-329.

12. Pignon JP, Bourhis J, Domenge C, Designe L: Chemotherapy added to locoregional treatment for head and neck squamous-cell carcinoma: three meta-analyses of updated individual data. MACH-NC Collaborative Group. Meta-Analysis of Chemotherapy on Head and Neck Cancer. Lancet 2000, 355:949-955.

13. Domenge C, Hill C, Lefebvre $J$, De Raucourt D, Rhein B, Wibault $P$, Marandas P, Coche-Dequeant B, Stromboni-Luboinski M, Sancho-Garnier H, Luboinski B: Randomized trial of neoadjuvant chemotherapy in oropharyngeal carcinoma. French Groupe d'Etude des Tumeurs de la Tete et du Cou (GETTEC). Br J Cancer 2000, 83:1594-1598.

14. Paccagnella A, Orlando A, Marchiori C, Zorat PL, Cavaniglia G, Sileni VC, Jirillo A, Tomio L, Fila G, Fede A, et al: Phase III trial of initial chemotherapy in stage III or IV head and neck cancers: a study by the Gruppo di Studio sui Tumori della Testa e del Collo. J Natl Cancer Inst 1994, 86:265-272.

15. Dabholkar M, Vionnet J, Bostick-Bruton F, Yu JJ, Reed E: Messenger RNA levels of XPAC and ERCC1 in ovarian cancer tissue correlate with response to platinum-based chemotherapy. J Clin Invest 1994, 94:703-708.

16. Murray D, Rosenberg E: The importance of the ERCC1/ERCC4[XPF] complex for hypoxic-cell radioresistance does not appear to derive from its participation in the nucleotide excision repair pathway. Mutat Res 1996, 364:217-226

17. Lord RV, Brabender J, Gandara D, Alberola V, Camps C, Domine M, Cardenal F, Sanchez JM, Gumerlock PH, Taron M, et al: Low ERCC1 expression correlates with prolonged survival after cisplatin plus gemcitabine chemotherapy in non-small cell lung cancer. Clin Cancer Res 2002, 8:2286-2291.

18. Kwon HC, Roh MS, Oh SY, Kim SH, Kim MC, Kim JS, Kim HJ: Prognostic value of expression of ERCC1, thymidylate synthase, and glutathione $\mathrm{S}$ transferase P1 for 5-fluorouracil/oxaliplatin chemotherapy in advanced gastric cancer. Ann Oncol 2007, 18:504-509.

19. Joshi MB, Shirota Y, Danenberg KD, Conlon DH, Salonga DS, Herndon JE, Danenberg PV, Harpole DH Jr: High gene expression of TS1, GSTP1, and ERCC1 are risk factors for survival in patients treated with trimodality therapy for esophageal cancer. Clin Cancer Res 2005, 11:2215-2221.

20. Metzger R, Leichman CG, Danenberg KD, Danenberg PV, Lenz HJ, Hayashi K, Groshen S, Salonga D, Cohen H, Laine L, et al: ERCC1 mRNA levels complement thymidylate synthase mRNA levels in predicting response and survival for gastric cancer patients receiving combination cisplatin and fluorouracil chemotherapy. J Clin Oncol 1998, 16:309-316.

21. Shirota Y, Stoehlmacher J, Brabender J, Xiong YP, Uetake H, Danenberg KD, Groshen S, Tsao-Wei DD, Danenberg PV, Lenz HJ: ERCC1 and thymidylate synthase mRNA levels predict survival for colorectal cancer patients receiving combination oxaliplatin and fluorouracil chemotherapy. J Clin Oncol 2001, 19:4298-4304.

22. Olaussen KA, Dunant A, Fouret P, Brambilla E, Andre F, Haddad V, Taranchon E, Filipits M, Pirker R, Popper HH, et al: DNA repair by ERCC1 in non-small-cell lung cancer and cisplatin-based adjuvant chemotherapy. N Engl J Med 2006, 355:983-991.

23. Lee JM: The synergistic effect of cigarette taxes on the consumption of cigarettes, alcohol and betel nuts. BMC Public Health 2007, 7:121.

24. Thomas SJ, Bain CJ, Battistutta D, Ness AR, Paissat D, Maclennan R: Betel quid not containing tobacco and oral cancer: a report on a case-control study in Papua New Guinea and a meta-analysis of current evidence. Int J Cancer 2007, 120:1318-1323.

25. Nair U, Bartsch H, Nair J: Alert for an epidemic of oral cancer due to use of the betel quid substitutes gutkha and pan masala: a review of agents and causative mechanisms. Mutagenesis 2004, 19:251-262.

26. Chiang WF, Liu SY, Yen CY, Lin CN, Chen YC, Lin SC, Chang KW: Association of epidermal growth factor receptor (EGFR) gene copy number amplification with neck lymph node metastasis in arecaassociated oral carcinomas. Oral Oncol 2008, 44:270-276.
27. Chen $H$, Chang JT, Liao CT, Wang HM, Hsieh LL, Cheng AJ: Prognostic significance of EGFR and Her-2 in oral cavity cancer in betel quid prevalent area cancer prognosis. Br J Cancer 2003, 89:681-686.

28. Handra-Luca A, Hernandez J, Mountzios G, Taranchon E, Lacau-St-Guily J, Soria JC, Fouret P: Excision repair cross complementation group 1 immunohistochemical expression predicts objective response and cancer-specific survival in patients treated by Cisplatin-based induction chemotherapy for locally advanced head and neck squamous cell carcinoma. Clin Cancer Res 2007, 13:3855-3859.

29. Jun HJ, Ahn MJ, Kim HS, Yi SY, Han J, Lee SK, Ahn YC, Jeong HS, Son YI, Baek JH, Park K: ERCC1 expression as a predictive marker of squamous cell carcinoma of the head and neck treated with cisplatin-based concurrent chemoradiation. Br J Cancer 2008, 99:167-172.

30. Fountzilas G, Bamias A, Kalogera-Fountzila A, Karayannopoulou G, Bobos M, Athanassiou E, Kalogeras KT, Tolis C, Tsekeris P, Papakostas P, et al: Induction chemotherapy with docetaxel and cisplatin followed by concomitant chemoradiotherapy in patients with inoperable non-nasopharyngeal carcinoma of the head and neck. Anticancer Res 2009, 29:529-538.

31. Kim MK, Cho KJ, Kwon GY, Park SI, Kim YH, Kim JH, Song HY, Shin JH, Jung HY, Lee GH, et al: Patients with ERCC1-negative locally advanced esophageal cancers may benefit from preoperative chemoradiotherapy. Clin Cancer Res 2008, 14:4225-4231.

32. Fountzilas G, Kalogera-Fountzila A, Lambaki S, Wirtz RM, Nikolaou A, Karayannopoulou G, Bobos M, Kotoula V, Murray S, Lambropoulos A, et al: MMP9 but Not EGFR, MET, ERCC1, P16, and P-53 Is Associated with Response to Concomitant Radiotherapy, Cetuximab, and Weekly Cisplatin in Patients with Locally Advanced Head and Neck Cancer. J Oncol 2009, 2009:305908.

33. Nix PG, Stafford N, Cawkwell L: Expression of XRCC1 and ERCC1 proteins in radioresistant and radiosensitive laryngeal cancer. Cancer Therapy 2004, 2:47-53.

34. Huang SM, Bock JM, Harari PM: Epidermal growth factor receptor blockade with C225 modulates proliferation, apoptosis, and radiosensitivity in squamous cell carcinomas of the head and neck. Cancer Res 1999, 59:1935-1940.

35. Huang SM, Harari PM: Modulation of radiation response after epidermal growth factor receptor blockade in squamous cell carcinomas: inhibition of damage repair, cell cycle kinetics, and tumor angiogenesis. Clin Cancer Res 2000, 6:2166-2174.

36. Nyati MK, Morgan MA, Feng FY, Lawrence TS: Integration of EGFR inhibitors with radiochemotherapy. Nat Rev Cancer 2006, 6:876-885.

37. Wanner G, Mayer C, Kehlbach R, Rodemann HP, Dittmann K: Activation of protein kinase Cepsilon stimulates DNA-repair via epidermal growth factor receptor nuclear accumulation. Radiother Oncol 2008, 86:383-390.

38. Dittmann KH, Mayer C, Ohneseit PA, Raju U, Andratschke NH, Milas L, Rodemann HP: Celecoxib induced tumor cell radiosensitization by inhibiting radiation induced nuclear EGFR transport and DNA-repair: a COX-2 independent mechanism. Int J Radiat Oncol Biol Phys 2008, 70:203-212.

39. Lo HW, Hsu SC, Ali-Seyed M, Gunduz M, Xia W, Wei Y, Bartholomeusz G, Shih JY, Hung MC: Nuclear interaction of EGFR and STAT3 in the activation of the iNOS/NO pathway. Cancer Cell 2005, 7:575-589.

40. Rabik CA, Dolan ME: Molecular mechanisms of resistance and toxicity associated with platinating agents. Cancer Treat Rev 2007, 33:9-23.

41. Balin-Gauthier D, Delord JP, Pillaire MJ, Rochaix P, Hoffman JS, Bugat R, Cazaux C, Canal P, Allal BC: Cetuximab potentiates oxaliplatin cytotoxic effect through a defect in NER and DNA replication initiation. Br J Cancer 2008, 98:120-128.

42. Prewett M, Deevi DS, Bassi R, Fan F, Ellis LM, Hicklin DJ, Tonra JR: Tumors established with cell lines selected for oxaliplatin resistance respond to oxaliplatin if combined with cetuximab. Clin Cancer Res 2007, 13:7432-7440.

\section{doi:10.1186/1479-5876-9-31}

Cite this article as: Chiu et al:: High ERCC1 expression predicts cisplatinbased chemotherapy resistance and poor outcome in unresectable squamous cell carcinoma of head and neck in a betel-chewing area. Journal of Translational Medicine 2011 9:31. 